\title{
Erratum
}

\section{Feeding on micro-algae in the invasive Ponto-Caspian amphipod Dikerogammarus villosus (Sowinsky 1984)}

Dirk Platvoet, Jaimie T.A. Dick, Nellie Konijnendijk and Gerard van der Velde

Aquatic Ecology

DOI 10.1007/s10452-005-9028-9

Be advised that Figure 2 and Figure 3 do not show correct labeling on the $y$-axis. The correct figures are shown below.

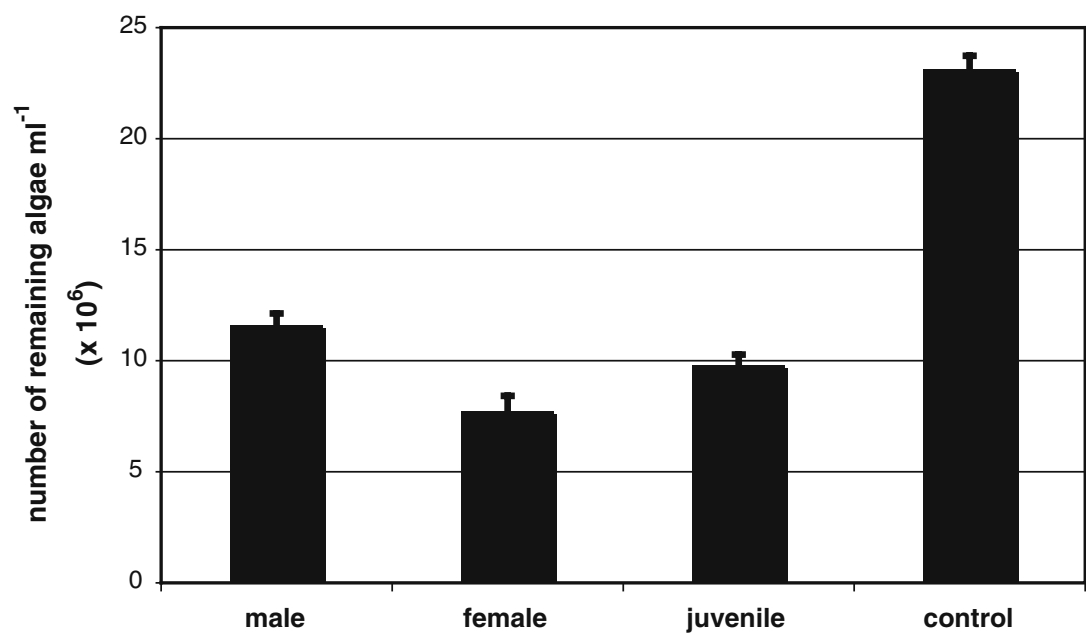

Figure 2. Mean number $(+\mathrm{SE})$ of micro algae remaining in containers after 7 days with, or without $D$. villosus.

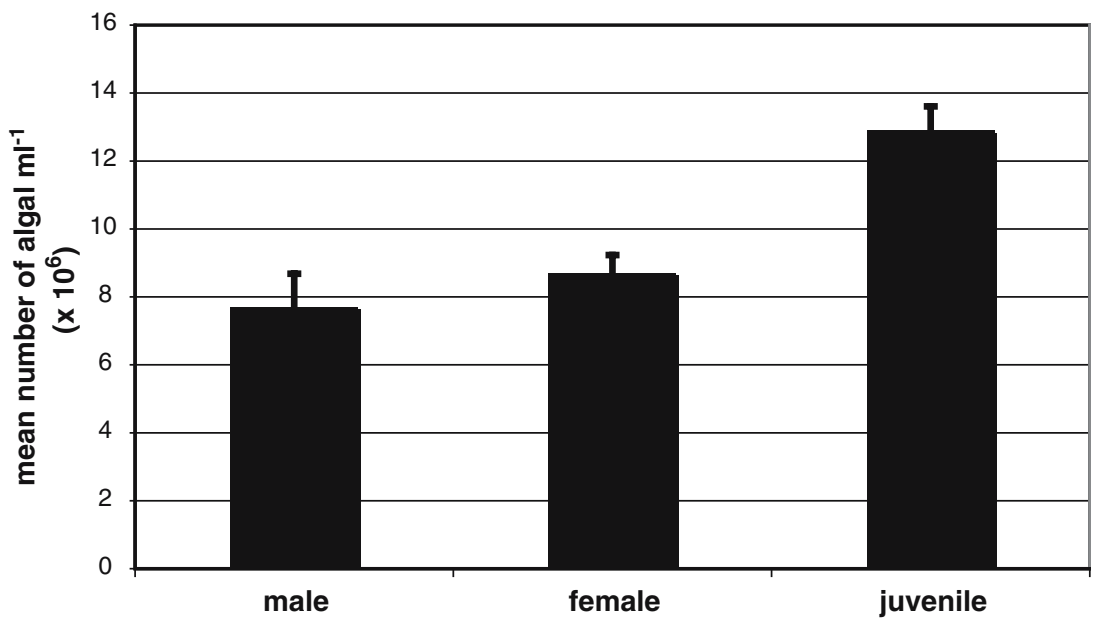

Figure 3. Mean number $(+\mathrm{SE})$ of algae $\mathrm{ml}^{-1}$ of cardiac stomach samples from D. villosus. 